\title{
HEPARIN COATING OF EXTRACORPOREAL CIRCUITS INHIBITS CONTACT ACTIVATION DURING CARDIAC OPERATIONS
}

Henk te Velthuis, $\mathrm{PhD}^{\mathrm{a}}$

Christophe Baufreton, $\mathrm{MD}^{\mathrm{b}}$

Piet G. M. Jansen, $\mathrm{MD}, \mathrm{PhD}^{\mathrm{c}}$

Caroline M. Thijs ${ }^{c}$

C. Erik Hack, MD, $\mathrm{PhD}^{\mathrm{a}}$

Augueste Sturk, $\mathrm{PhD}^{\mathrm{d}}$

Charles R. H. Wildevuur, MD, $\mathrm{PhD}^{\mathrm{c}}$

Daniel Y. Loisance, $\mathrm{MD}^{\mathrm{b}}$
Objective: Heparin coating reduces complement activation on the surface of extracorporeal circuits. In this study we investigated its effect on activation of the contact system in 30 patients undergoing coronary artery bypass grafting with the use of a heparin-coated (Duraflo II, Baxter Healthcare Corp., Edwards Division, Santa Ana, Calif; $n=15$ ) or an uncoated extracorporeal circuit $(n=15)$. Methods: Plasma markers that reflect activation of contact (kallikrein-C1-inhibitor complexes), coagulation (prothrombin fragments $F 1+2$ ), or fibrinolytic (plasmin- $\alpha_{2}$-antiplasmin complexes) systems were determined before and during the operation. The generation of kallikrein-C1-inhibitor complexes was reduced by $62 \%(p=$ 0.06) after the onset of cardiopulmonary bypass and by $43 \%(p=0.026)$ after the cessation of bypass in the group in which a heparin-coated circuit was used compared with the group in which the circuit was uncoated. Generation was reduced by $58 \%(p=0.06)$ when the ratio of kallikreinC1-inhibitor to prekallikrein after onset of bypass was considered. We detected significant increases in $\mathrm{F} 1+2$ levels in both groups and increases in plasmin- $\alpha_{2}$-antiplasmin complexes in the heparin-coated group at cessation of bypass, but no intergroup differences were observed. Thus use of heparin-coated extracorporeal circuits during cardiac operations reduces formation of kallikrein-C1-inhibitor complexes when compared with use of uncoated circuits. The heparin coating is not accompanied by similar reductions in coagulation or fibrinolysis, suggesting that thrombin and plasmin formation during cardiopulmonary bypass occurs mainly independently of the contact system activation. (J Thorac Cardiovasc Surg 1997; 114:117-22)
D uring cardiopulmonary bypass (CPB) the extensive contact between blood and the surface of the extracorporeal circuit (ECC) results in activa-

From the Department of Pathophysiology of Plasma Proteins, Central Laboratory of The Netherlands Red Cross Blood Transfusion Service, Amsterdam, The Netherlands, ${ }^{a}$ the Department of Thoracic and Cardiovascular Surgery, C.N.R.S. URA 1431 and Association Claude Bernard, Henri Mondor Hospital, Créteil, France, ${ }^{b}$ the Centre for Cardiopulmonary Surgery Amsterdam, Amsterdam, The Netherlands, ${ }^{c}$ and the Department of Clinical Chemistry, University Hospital Leiden, Leiden, The Netherlands. ${ }^{d}$

Received for publication July 19, 1996; revisions requested Sept. 12, 1996; revisions received Jan. 30, 1997; accepted for publication Jan. 31, 1997.

Address for reprints: H. te Velthuis, PhD, Central Laboratory of The Netherlands Red Cross Blood Transfusion Service, Department of Pathophysiology of Plasma Proteins, P.O. Box 9190, 1006 AD Amsterdam, The Netherlands.

Copyright (C) 1997 by Mosby-Year Book, Inc.

$0022-5223 / 97 \$ 5.00+0 \quad \mathbf{1 2 / 1 / 8 0 9 3 9}$ tion of various humoral and cellular cascades. Blood-material interaction causes activation of clotting in recipients, which necessitates simultaneous pretreatment with coagulation inhibitors such as heparin sulfate. This observation has led to the development of surface coatings with heparin on the vital compartments of the ECCs. Since heparincoated ECCs became commercially available, studies have been performed regarding the effects of heparin coating on the generation of complement activation products. ${ }^{1-3}$ Remarkably, no clinical study has so far been published regarding its effect on activation of the contact system, that is, the initiation of the intrinsic pathway of coagulation and fibrinolysis.

The contact system is initiated when factor XII (FXII, Hageman factor) binds to negatively charged surfaces and subsequently becomes activated (FXIIa). ${ }^{4,5}$ FXIIa can cleave factor XI (FXI) of the intrinsic coagulation pathway into FXIa, which 
eventually may trigger thrombin formation and clotting. FXIIa can also cleave prekallikrein into kallikrein, which cleaves high-molecular-weight kininogen to release bradykinin, a nonapeptide with notorious vasodilating properties. ${ }^{4,5}$ FXIIa may further be cleaved by kallikrein into Hageman factor fragment ( $\beta$-FXIIa). Hageman factor fragment (and not FXIIa) in its turn may enzymatically activate the first component of the classic complement pathway, $\mathrm{C} 1{ }^{6}$ Contact activation is mainly controlled by $\mathrm{C} 1-$ esterase inhibitor (C1Inh), which forms stable and detectable complexes with FXIIa, FXIa, and kallikrein., ${ }^{7,8}$

To evaluate the activation of the contact system during CPB and the effect of heparin coating on this activation, we performed a randomized trial in 30 patients undergoing coronary bypass operations who were connected to either a heparin-coated or an uncoated ECC. We determined plasma markers for contact activation, coagulation, and fibrinolysis before and during the operation.

\section{Materials and methods}

Patients and study design. We performed a prospective study to determine whether heparin coating of ECCs reduced contact activation. Therefore 30 patients undergoing elective coronary bypass operations were enrolled and randomly allocated to be connected to either a heparin-coated (15 patients) or an uncoated ECC (15 patients). The study was performed at the Department of Thoracic and Cardiovascular Surgery, C.N.R.S. URA 1431, and Association Claude Bernard, Henri Mondor Hospital, Créteil, France, and was approved by the local medical and ethics committee. Entry criteria for the study were ingestion of aspirin stopped for at least 7 days before the operation and left ventricular injection fraction exceeding $30 \%$. Exclusion criteria were a history of arrhythmia, impaired organ function other than myocardial ischemia, and the presence of active inflammatory disease. Patients receiving aprotinin during the operation were excluded from the study.

Techniques of anesthesia and extracorporeal circulation. Anesthesia was induced and maintained with phenoperidine and droperidol. The ECC consisted of a roller pump (Sarns 9000, 3M Health Care Group, Ann Arbor, Mich.), a closed venous reservoir, hollow fiber oxygenator (Univox, Baxter Healthcare Corp., Irvine, Calif.), a cardiotomy reservoir (Baxter BCR 3500), and an arterial filter (Baxter AF-1400). In the heparin-coated ECC group, all compartments of the circuit contained surfacebound heparin (Duraflo IL, Baxter). The circuits were primed with $1000 \mathrm{ml}$ of lactated Ringer's solution, $60 \mathrm{ml}$ of $8.4 \%$ sodium bicarbonate, 5000 IU of heparin, and 1 gm of potassium chloride. CPB was performed with core cooling to $28^{\circ} \mathrm{C}$ and nonpulsatile flow of $2.4 \mathrm{~L} \cdot \mathrm{min}^{-1}$. $\mathrm{m}^{-2}$. During aortic crossclamping, the myocardium was protected with antegrade cold cardioplegia. Heparin (300
$\mathrm{IU} \cdot \mathrm{kg}^{-1}$ ) was administered before cannulation. Additional heparin was administered if the activating clotting time (ACT, Hemotec, Inc., Englewood, Colo.) was less than 600 seconds. After cessation of $\mathrm{CPB}$, protamine sulfate $(1 \mathrm{mg} / 100 \mathrm{IU}$ heparin) was administered intravenously. Blood transfusion was indicated when the hematocrit value was below $25 \%$.

Biochemical parameters. Blood samples were taken from the radial artery or from the arterial line of the ECC. The samples were immersed in melting ice immediately after collection and processed within 1 hour. Platelet-poor plasma samples were prepared by centrifugation for 15 minutes at $1500 \mathrm{~g}$ and stored at $-70^{\circ} \mathrm{C}$. Blood samples were collected in tubes containing ethylenedinitrotetra acetate for anticoagulation (final concentration $10 \mathrm{mmol} / \mathrm{L}$ ). Plasma samples for contact activation markers were collected in tubes containing ethylenedinitrotetra acetate supplemented with $0.05 \%(\mathrm{w} / \mathrm{v})$ of hexadimethrine bromide (Polybrene; Janssen Pharmaceutica, Beerse, Belgium). The blood samples were taken before induction of anesthesia, 10 minutes after onset of $\mathrm{CPB}$, and within minutes after cessation of CPB.

Factor XIIa-C1-esterase inhibitor (FXIIa-C1Inh) and kallikrein-C1-esterase inhibitor (kal-C1Inh) complexes were assayed by radioimmunoassay as described before. ${ }^{8}$ In brief, a monoclonal antibody that specifically binds complexed C1Inh (KOK 12) was coupled to CNBr-Sepharose 4B (Pharmacia Biotech. AB, Uppsala, Sweden) and incubated with plasma samples. Bound FXIIa-C1Inh or kal-C1Inh complexes were quantitated by subsequent incubation with either ${ }^{125}$ I-labeled polyclonal anti-FXII or ${ }^{125}$ I-labeled anti-kallikrein antibodies, respectively. Results obtained with tested plasma were calculated by reference to an in-house standard curve that consisted of kaolin-stimulated pooled plasma. Prekallikrein antigen was assayed by radioimmunoassay as described before. In brief, plasma samples were incubated with a specific anti-prekallikrein monoclonal antibody (K15) coupled to sepharose. Bound prekallikrein was quantitated with ${ }^{125} \mathrm{I}$ labeled polyclonal antibodies (636) against prekallikrein. We calculated the ratio between the activation product kallikrein (kal-C1Inh) and its precursor prekallikrein to correct for dilution.

Plasmin- $\alpha_{2}$-antiplasmin complexes were assayed by radioimmunoassay as described before. ${ }^{10}$ In brief, samples were incubated with a Sepharose-coupled monoclonal antibody AAP-11, which is directed against complexed and inactivated $\alpha_{2}$-antiplasmin. Bound plasmin- $\alpha_{2}$-antiplasmin complexes were quantitated with ${ }^{125}$ I-labeled monoclonal antibodies against plasmin (AP1). Serial dilutions of urokinase-activated pooled plasma served as a standard. Prothrombin fragment F1+2 was measured with a commercially available enzyme-linked immunosorbent assay (F1+2 ELISA, Behringwerke, Marburg, Germany).

Data management and statistics. Data were analyzed with STATVIEW SE ${ }^{+}$Graphics computer software (Abacus Concepts, Inc., Berkeley, Calif.). Comparisons within the groups were assessed with the paired $t$ test and between the groups with regression analysis. The adjusted $\mathrm{R}^{2}$ for the regression analysis is given and the coefficients are expressed within $95 \%$ confidence limits. Dichotomous variables were analyzed with Fisher's exact test. In all 
Table I. Patient's characteristics, surgical data, and blood loss

\begin{tabular}{lccc}
\hline & \multicolumn{3}{c}{$\begin{array}{c}\text { Heparin- } \\
\text { coated }\end{array}$} \\
& $E C C$ & $E C C$ & $p$ Value \\
\hline Age (yr) & $64 \pm 3.4$ & $65 \pm 4.0$ & NS \\
Sex (female/male) & $1 / 14$ & $5 / 10$ & NS \\
Height (m) & $1.67 \pm 5$ & $1.65 \pm 6$ & NS \\
Weight (kg) & $77 \pm 7$ & $67 \pm 6$ & 0.02 \\
Body surface area $\left(\mathrm{m}^{2}\right)$ & $1.93 \pm 0.1$ & $1.78 \pm 0.1$ & 0.02 \\
Duration of crossclamping & $71 \pm 13$ & $71 \pm 12$ & NS \\
$\quad$ (min) & & & \\
Duration of CPB (min) & $129 \pm 18$ & $138 \pm 26$ & NS
\end{tabular}

Data are presented as means $\pm 95 \%$ confidence of the mean. NS, Not significant.

cases a two-sided probability less than 0.05 was considered to be significant. Data are presented as means $\pm 95 \%$ confidence interval of the mean and are not corrected for hemodilution unless mentioned otherwise.

\section{Results}

Demographic data and surgical data of both groups are listed in Table I. No complications occurred and all patients survived. The patients were randomly allocated to be connected either to an uncoated or a heparin-coated ECC. The patients in the uncoated ECC group appeared heavier $(p=$ $0.02)$ and had a larger body surface area $(p=0.02)$.

After onset of CPB, levels of kal-C1Inh complexes were $62 \%$ lower in the heparin-coated group $(p=0.058)$. After cessation of CPB, levels of kal-C1Inh complexes were significantly lower in the heparin-coated ECC group than in the uncoated group (difference 43\%; $p=0.026$ ) (Fig. 1, Table II). This difference in kal-C1Inh was related only to the heparin coating (adjusted $\mathrm{R}^{2}: 0.41 ; 95 \%$ confidence interval of the coefficient $[\mathrm{Cl}]:-185,-16)$, while baseline (95\% CI: $-0.054,0.38$ ), duration of CPB (95\% CI: $-0.36,2.2)$, and body weight $(95 \%$ CI: -38 , 4.8) did not contribute. Thus the patient's body weight did not contribute to differences found in contact activation between the groups. After onset of CPB and at cessation of CPB, prekallikrein concentrations dropped equally in the two groups (Table II), parallel with dilution, without significant intergroup differences. Also, after correction for hematocrit values, prekallikrein levels slightly dropped by $6 \%$ to $10 \%(p>0.05)$ in both groups during CPB (Table II). We calculated the ratio between kal-C1Inh complex and prekallikrein. Only $0.025 \%$ to $0.05 \%$ of all prekallikrein is cleaved into kallikrein. In the heparin-coated ECC group, this
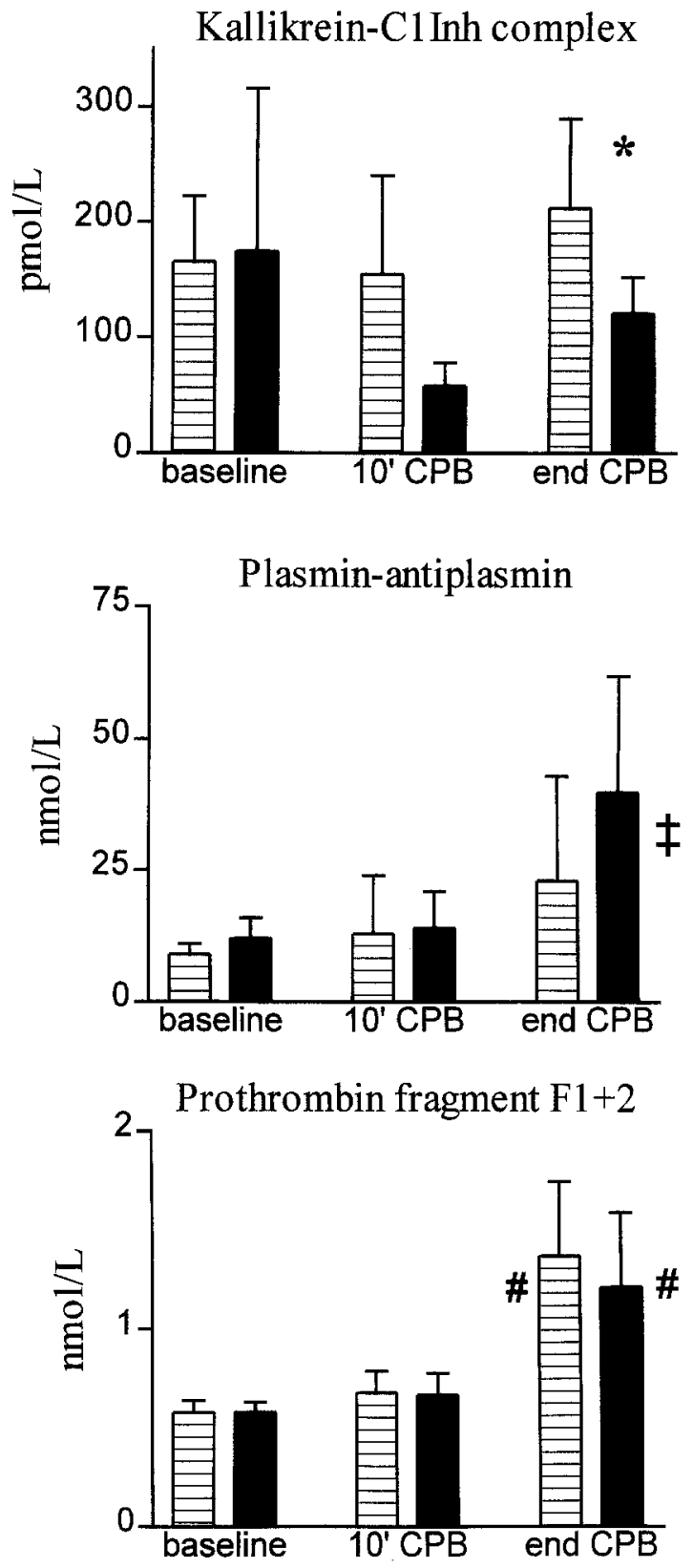

Fig. 1. Kallikrein-C1-inhibitor complexes, plasmin-antiplasmin complexes, and $\mathrm{F} 1+2$ concentrations during CPB. Data presented are means with $95 \%$ confidence interval of the mean. Open bars, Uncoated ECCs; closed bars, heparin-coated ECCs. ${ }^{*} p=0.026$, intergroup differences; $\# p=0.014 ; \ddagger p=0.015$ compared with preoperative values.

ratio remained unchanged during $\mathrm{CPB}$, whereas in the uncoated ECC group a significant increase was determined at cessation of CPB $(p=0.014)$. Most of the values for FXIIa-C1Inh complexes were below 
Table II. Blood activation markers and hematocrit values in patients undergoing CPB with an uncoated or a heparin-coated ECC

\begin{tabular}{|c|c|c|c|c|}
\hline & $E C C$ & Preoperative & After start of $C P B$ & End of $C P B$ \\
\hline \multirow[t]{2}{*}{ Hematocrit (\%) } & Uncoated & $41(1.5)$ & $29(3.2) \dagger$ & $30(1.9) \dagger$ \\
\hline & Heparin coated & $38(3.1)$ & $28(3.0) \dagger$ & $29(1.3) \dagger$ \\
\hline \multirow[t]{2}{*}{ PK (nmol/L) } & Uncoated & $407(61)$ & $261(59) \dagger$ & $259(33) \dagger$ \\
\hline & Heparin coated & $367(59)$ & $243(34) \dagger$ & $237(38) \dagger$ \\
\hline \multirow[t]{2}{*}{ PK corr. Het } & Uncoated & $407(61)$ & $373(59)$ & $373(33)$ \\
\hline & Heparin coated & $367(59)$ & $349(34)$ & $333(38)$ \\
\hline \multirow[t]{2}{*}{ Kal-C1Inh $(\mathrm{pmol} / \mathrm{L})$} & Uncoated & $165(57)$ & $154(86)$ & $212(77)^{*}$ \\
\hline & Heparin coated & $174(142)$ & $58(20)$ & $120(32)$ \\
\hline \multirow[t]{2}{*}{ Ratio Kal-C1I/PK $\left(\times 10^{-4}\right)$} & Uncoated & $4.3(1.7)$ & $5.7(2.6)$ & $8.7(3.2) \neq$ \\
\hline & Heparin coated & $4.2(2.5)$ & $2.4(0.7)$ & $5.3(1.6)$ \\
\hline \multirow[t]{2}{*}{$\mathrm{F} 1+2(\mathrm{nmol} / \mathrm{L})$} & Uncoated & $0.58(0.06)$ & $0.68(0.11)$ & $1.37(0.38) \S$ \\
\hline & Heparin coated & $0.58(0.05)$ & $0.67(0.11)$ & $1.21(0.38) \S$ \\
\hline \multirow[t]{2}{*}{$\mathrm{PAP}(\mathrm{nmol} / \mathrm{L})$} & Uncoated & $9(2)$ & $13(11)$ & $23(20)$ \\
\hline & Heparin coated & $12(4)$ & $14(7)$ & $40(22) \|$ \\
\hline
\end{tabular}

Data are presented as means (95\% confidence interval of the mean). PK, prekallikrein; PK corrected for hematocrit according to the equation: $\mathrm{PK}($ corrected $)=\mathrm{PK}($ sample $) \cdot \mathrm{Hct}($ baseline $) / \mathrm{Hct}($ sample $) ; P A P$, plasmin- $\alpha_{2}$-antiplasmin.

${ }^{*} p=0.026$, intergroup differences.

$\dagger p=0.001$.

$\ddagger p=0.014$.

$\S p=0.003$.

$\| p=0.015$ compared with preoperative.

the detection limit of the assay, which made it impossible to assess differences between the groups.

We did not determine any intergroup differences in $F 1+2$ or plasmin- $\alpha_{2}$-antiplasmin (Fig. 1, Table II). In both groups, $\mathrm{F} 1+2$ concentrations increased significantly at cessation of CPB $(p=0.003)$. Plasmin- $\alpha_{2}$-antiplasmin levels, however, increased only in the heparin-coated group at cessation of $\mathrm{CPB}$ $(p=0.015)$. No correlations were found between $\mathrm{Fl}+2$, plasmin- $\alpha_{2}$-antiplasmin, or kal-C1Inh complexes.

\section{Discussion}

Despite anticoagulant treatment with heparin, we detected clotting activation as reflected by the generation of the prothrombin fragment $\mathrm{F} 1+2$ during CPB. In addition, plasmin and kallikrein were formed during CPB as indicated by the formation of plasmin-antiplasmin and kal-C1Inh complexes, respectively. Although activation of the contact system is generally believed to manifest itself strongly during blood-material interaction, as for example during CPB, only Wachtfogel and associates ${ }^{11}$ demonstrated kallikrein formation in patients undergoing CPB, but only after the ECC had been disconnected. Furthermore, Kongsgaard, ${ }^{12}$ De Smet, ${ }^{13}$ and their associates reported a transient decrease in kallikrein-inhibiting capacity immediately after heparinization and onset of CPB. Thus surprisingly little evidence for contact activation during CPB exists, although during simulated ECC kal-C1Inh complexes are formed immediately after the start of the ECC procedure. ${ }^{11,14,15}$ The increase in the ratio between kal-C1Inh and prekallikrein in our patients, when connected to an uncoated circuit, is consistent with contact activation during simulated ECC. The increase, however, was only moderate, which in part may have been due to rapid clearance of the kalC1Inh complexes.

In this study, we studied patients connected to either a heparin-coated or an uncoated ECC and found an almost significant reduction by $62 \%$ in kal-C1Inh complexes $(p=0.06)$ in the heparincoated ECC group. This drop in kal-C1Inh complexes in the heparin-coated ECC group was not explained by a higher dilution at the onset of CPB, because in both groups an identical ratio of kalC1Inh complexes to prekallikrein was found before and after onset of CPB and the degree of dilution was identical in both groups, as reflected by similar changes in hematocrit value (see Table II). Evidently, heparin coating had almost significantly reduced kallikrein formation already after the onset of $\mathrm{CPB}$, but significantly at the end of CPB. The difference at the end of CPB was explained only by the use of heparin coating, whereas blood-contact time (duration of CPB), preoperative levels, and the patient's body weight did not contribute. 
The question can be raised by what mechanism heparin coating exercises its activity on the contact system. The decreased formation of kallikrein in the heparin-coated ECC group cannot be explained by the potentiating effect of heparin on C1Inh activity. Although heparin does potentiate $\mathrm{C} 1 \mathrm{Inh}$ regarding inhibition of complement $\mathrm{C} 1 \mathrm{~s}$ and $\mathrm{C} 1 \mathrm{r}$ activity ${ }^{16}$ and also of the clotting protease $\mathrm{FXIa}^{7}{ }^{7}$ it does not change the rate of FXII or kallikrein inhibition by C1Inh. ${ }^{17,}{ }^{18}$ However, in the presence of unfractionated heparin and high-molecular-weight kininogen, kallikrein is mainly inhibited by antithrombin III $(50 \%$ to $53 \%),{ }^{19,20}$ while inhibition by C1Inh drops from $45 \%$ (without heparin) to $24 \%$ (with heparin) and that by $\alpha_{2}$-macroglobulin from $55 \%$ to $22 \%$. Thus a shift in kallikrein-inhibitor complexes after heparinization in favor of kallikrein-antithrombin III complexes might explain the drop in kal-C1Inh complexes after the onset of CPB. In the uncoated ECC group, this drop is masked by additional kallikrein formation on the surface of the circuit. The net result is more or less stable concentrations of complexes. Consistent with this finding are the observations that antithrombin III, and not C1Inh, seems to be the most important antiprotease during the control of contact activation on heparin-coated surfaces in vitro. Sanchez and colleagues ${ }^{21}$ observed clot formation on the surface of heparin-coated polyethylene tubings with recalcified plasma depleted of antithrombin III, but not with C1Inhdepleted plasma. Moreover, removal of antithrombin III resulted in extensive activation of FXII, whereas C1Inh depletion had lesser effects. ${ }^{21}$ The reduced generation of kal-C1Inh complexes may thus be due to enhanced activity of antithrombin III by the surface-immobilized heparin that inhibits kallikrein activity, enhancement of FXII activation, and thus contact activation.

A second, and more simple, explanation would be that heparin covers the surface of the circuits and thus prevents FXII binding.

It is believed that during CPB thrombin formation is mainly initiated through the activation of the contact system. Intensive contact between blood and the surface of the ECC initiates activation of FXII and, subsequently, that of factors of the intrinsic pathway of coagulation. Heparin coating reduces material-dependent thrombin formation by an antithrombin III-dependent mechanism. ${ }^{22,}{ }^{23}$ However, the application of heparin-coated ECCs did not reduce thrombin formation during $\mathrm{CPB}$, as we assessed by measuring the course of prothrombin fragment $\mathrm{F} 1+2$. Considering that contact activation was reduced by heparin coating of the circuits, our findings imply that thrombin formation occurs independently from contact activation. This is supported by several other studies. ${ }^{24-26}$ Thrombin formation during CPB probably mainly occurs via the tissuefactor pathway and may be independent of the use of heparin-coated ECCs. In agreement herewith, patients with a severe FXII deficiency undergoing cardiac surgery show comparable thrombin formation to normal individuals. ${ }^{27,28}$ Conversely, activation of the contact system seems to be related to fibrinolysis. Patients with a severe FXII deficiency (FXII < 1\%) demonstrate impaired fibrinolytic activity after desamino D-arginine vasopressin stimulation $^{29}$ and may have a higher incidence of thromboembolism. ${ }^{30}$ In the present study, however, we found no direct support for involvement of the contact system in fibrinolysis. Although kal-C1Inh complexes in the heparin-coated ECC group were significantly reduced, plasmin $\alpha_{2}$-antiplasmin levels increased instead of reduced.

In summary, we found reduced formation of kallikrein in patients connected to a heparin-coated $\mathrm{ECC}$, and no effect on thrombin formation. Thus this study further supports the hypothesis that thrombin formation during cardiac surgery is not induced only via the intrinsic pathway of coagulation. Additionally, we also found no evidence for involvement of contact activation in plasmin formation. Thus the contribution and the clinical relevance of the FXII-induced pathway on blood activation in patients undergoing cardiac surgery remains to be determined.

We thank Anke J. M. Eerenberg-Belmer, Gerard van Mierlo, and Rene J. Berckmans for their assistance with the assays.

\section{REFERENCES}

1. Jansen PGM, te Velthuis H, Huybreghts RAJM, et al. Reduced complement activation and improved postoperative performance after cardiopulmonary bypass with heparincoated circuits. J Thorac Cardiovasc Surg 1995;110:829-34.

2. Te Velthuis H, Jansen PGM, Hack CE, Eijsman L, Wildevurur CRH. Specific complement inhibition with heparincoated extracorporeal circuits. Ann Thorac Surg 1996;61: 1153-7.

3. Videm V, Svennevig JL, Fosse E, Semb G, Østerud A Mollnes TE. Reduced complement activation with heparincoated oxygenator and tubings in coronary bypass operations. J Thorac Cardiovasc Surg 1992;103:806-13.

4. Kaplan AP, Silverberg M. The coagulation-kinin pathway of human plasma. Blood 1987;70:1-15.

5. Colman RW. Surface-mediated defense reactions: the 
plasma contact activation system. J Clin Invest 1984;73:1249. 53.

6. Ghebrehiwet B, Silverberg M, Kaplan AP. Activation of classical pathway of complement by Hageman factor fragment. J Exp Med 1981;153:665-76.

7. Wuillemin WA, Minnema M, Meijers JCM, et al. Inactivation of factor XIa in human plasma assessed by measuring factor XIa-protease inhibitor complexes: major role for C1inhibitor. Blood 1995;85:1517-26.

8. Nuijens JH, Huijbreghts CCM, Eerenberg-Belmer AJM, et al. Quantitation of plasma factor XIIa-C1-inhibitor and kallikrein-C1-inhibitor complexes in sepsis. Blood 1988;72: 1841-1848.

9. Nuijens JH, Huijbreghts CCM, Cohen B, et al. Detection of activation of the contact system of coagulation in vitro and in vivo: quantitation of Hageman factor-C1-inhibitor and kallikrein-C1-inhibitor complexes by specific radioimmunoassays. Thromb Haemost 1987;58:778-84.

10. Levi $M$, de Boer JP, Roem D, ten Cate JW, Hack CE. Plasminogen activation in vivo upon intravenous infusion of DDAVP: quantitative assessment of plasmin- $\alpha_{2}$-antiplasmin complex with a novel monoclonal antibody based radioimmunoassay. Thromb Haemost 1992;67:111-6.

11. Wachtfogel YT, Harpel PC, Edmunds H, Colman RW. Formation of C1s-C1-inhibitor, kallikrein-C1-inhibitor and plasmin- $\alpha_{2}$-plasmin-inhibitor complexes during cardiopulmonary bypass. Blood 1989;73:468-71.

12. Kongsgaard UE, Smith-Erichsen N, Geiran O, Amundsen E, Mollnes TE, Garred P. Different activation patterns in the plasma kallikrein-kinin and complement systems during coronary bypass surgery. Acta Anaesthesiol Scand 1989;33: 343-7.

13. De Smet AAEA, ChangNjoek JM, van Oeveren W, et al. Increased anticoagulation during cardiopulmonary bypass by aprotinin. J Thorac Cardiovasc Surg 1990;100:520-7.

14. Wachtfogel YT, Kucich U, Hack CE, et al. Aprotinin inhibits the contact, neutrophil, and platelet activation systems during simulated extracorporeal perfusion. J Thorac Cardiovasc Surg 1993;106: 1-10.

15. Wachtfogel YT, Hack CE, Nuijens JH, et al. Selective kallikrein inhibitors after human neutrophil elastase release during extracorporeal circulation. Am J Physiol 1995;268: H1352-7.

16. Rent RR, Myhrman R, Fiedel BA, Gewurz H. Potentiation of $\mathrm{C} \overline{1}$ esterase inhibitory activity by heparin. Clin Exp Immunol 1976;23:264-71.

17. Pixley RA, Schmaier A, Colman RW. The effect of factor XII activating compounds on factor XIIa and factor XIIf inhibition by $\mathrm{C} 1$ inhibitor. Fed Proc 1986;45:1638A.
18. Nilsson $\mathrm{T}$. On the interaction between kallikrein and $\mathrm{C} 1$ esterase inhibitor. Thromb Haemost 1983;49:193-5.

19. Olson ST, Sheffer R, Francis AM. High molecular weight kininogen potentiates the heparin-accelerated inhibition of plasma kallikrein by antithrombin: role for antithrombin in the regulation of kallikrein. Biochemistry 1993;32:12136-47.

20. Olson ST, Francis AM, Sheffer R, Choay J. Parallel mechanism of high molecular weight kininogen action as a cofactor in kallikrein inactivation and prekallikrein activation reactions. Biochemistry 1993;32:12148-59.

21. Sanchez J, Elgue G, Riesenfeld J, Olsson P. Control of contact activation on endpoint immobilized heparin: the role of antithrombin and the specific antithrombin-binding sequence. J Biomed Mater Res 1995;29:655-61.

22. Kodama K, Pasche B, Olsson P, et al. Antithrombin III binding to surface immobilized heparin and its relation to FXa inhibitors. Thromb Haemost 1987;58:1064-7.

23. Pasche B, Kodama K, Larm O, Olsson P, Swedenborg J. Thrombin inactivation on surfaces with covalently bonded heparin. Thromb Res 1986;44:739-48.

24. Wagner WR, Johnson PC, Thompson KA, Marrone GC. Heparin coated cardiopulmonary bypass circuits: hemostatic alterations and postoperative blood loss. Ann Thorac Surg 1994;58:734-41.

25. Øvrum E, Brosstad F, Holen EA, Tangen G, Abdelnoor M. Effects on coagulation and fibrinolysis with reduced versus full systemic heparinization and heparin-coated cardiopulmonary bypass. Circulation 1995;92:2579-84.

26. Gorman RC, Ziats NP, Koneti A, et al. Surface-bound heparin fails to reduce thrombin formation during clinical cardiopulmonary bypass. J Thorac Cardiovasc Surg 1996;111: $1-12$.

27. Moorman RM, Reynolds DS, Comunale ME. Management of cardiopulmonary bypass in a patient with congenital factor XII deficiency. J Cardiothorac Vasc Anesth 1993;7:452-4.

28. Burman JF, Chung HI, Lane DA, Philippou H, Adami A, Lincoln JCR. Role of factor XII in thrombin generation and fibrinolysis during cardiopulmonary bypass. Lancet 1994;344: 1192-3.

29. Levi M, Hack CE, de Boer JP, Brandjes DPM, Büller HR, ten Cate JW. Reduction of contact activation related fibrinolytic activity in factor XII deficient patients: further evidence for the role of the contact system in fibrinolysis in vivo. J Clin Invest 1991;88:1155-60.

30. Lammle B, Wuillemin WA, Huber I, et al. Thromboembolism and bleeding tendency in congenital factor XII deficiency: a study on 74 subjects from 14 Swiss families. Thromb Haemost 1991;65:117-21. 